\title{
Freqüência e patologia das infecções causadas por nematóides e cestóides em galinhas-d'angola (Numida meleagris Linnaeus, 1758) criadas extensivamente no estado do Rio de Janeiro, Brasil
}

\author{
Frequency and pathology of infeccions caused by nematodes and \\ cestodes in free ranged reared guinea fowls (Numida meleagris \\ Linnaeus, 1758) in the state of Rio de Janeiro, Brazil
}

\author{
Rodrigo Caldas Menezes, ${ }^{\star}$ Dalton Garcia de Mattos Júnior, ${ }^{\star \star}$ Rogério Tortelly ${ }^{\star \star \star}$
}

\section{Resumo}

Foi realizada uma pesquisa sobre as helmintoses que ocorrem em galinhas-d'angola criadas extensivamente no estado do Rio de Janeiro, através de exames clínicos, necropsias e exames histopatológicos de 36 aves. Os nematóides identificados com as respectivas prevalências e intensidades médias de infecção foram: Heterakis gallinarum 100,0\% e 194,08; Ascaridia numidae 75,0\% e 48,80; Capillaria spp. 52,8\% e 30,08; Dispharynx nasuta 44,4\% e 39,50; Eucoleus perforans 5,5\% e 0,55; Oxyspirura mansoni 2,8\% e 0,08. Raillietina (Paroniella) magninumida foi o único cestóide identificado, com prevalência de $47,2 \%$ e intensidade média de infecção de 20,33 . A. numidae, $D$. nasuta e $E$. perforans foram considerados os helmintos mais patogênicos. O nematóide Dispharynx nasuta foi registrado pela primeira vez no Brasil, neste hospedeiro.

Palavras-chave: galinha-d'angola; nematóides; cestóides; patologia.

\begin{abstract}
A survey of the helminthoses which occur in free range reared guinea fowls in the state of Rio de Janeiro was performed based on clinical examination, necropsies and histopathologic examination of $\mathbf{3 6}$ guinea fowls. The especies of nematodes indentified and their prevalence and intensity of infection were the following: Heterakis gallinarum 100,0\% and 194,08; Ascaridia numidae 75,0\% and 48,80; Capillaria spp. 52,8\% and 30,08; Dispharynx nasuta 44,4\% and 39,50; Eucoleus perforans 5,5\% and 0,55; Oxyspirura mansoni $2,8 \%$ and 0,08 . The only especie of cestode present was Raillietina (Paroniella) magninumida with $47,2 \%$ of prevalence and 20,33 of intensity of infection. A. numidae, $D$. nasuta e $E$. perforans were considered the most pathogenic helminthes. The nematode Dispharynx nasuta was for the first time reported in guinea fowls in Brazil.
\end{abstract}

Keywords: guinea fowl; nematodes; cestodes; pathology.

\section{Introdução}

A galinha-d'angola é uma ave de origem africana da ordem dos Galliformes. Esta ave foi pela primeira vez domesticada, há séculos, pelos gregos e romanos para servir como fonte de alimento (León e Soldevila, 1978). Ela foi introduzida no Brasil pelos colonizadores portugueses, sendo sua criação bastante difundida em todo território nacional, principalmente no nordeste brasileiro (Kiss e Ramos, 1996). Segundo Fabichak (1997), países como a França e Rússia são os principais consumidores mundiais de sua carne, que é muito apreciada em vários países.
Atualmente, no Brasil, a criação de galinhas-d'angola tem-se revelado uma alternativa econômica que vem atraindo cada vez mais criadores interessados em abastecer hotéis e restaurantes finos com sua carne e também em fornecê-las para ornamentar sítios e fazendas.

$\mathrm{Na}$ lista mais recente sobre a ocorrência e distribuição geográfica dos helmintos de animais domésticos do Brasil, Costa et al. (1986) listaram nove helmintos parasitas de galinhad'angola. Esse número é considerado pequeno, se comparado aos 48 helmintos já registrados em galinhas domésticas, segundo esta mesma lista.

\footnotetext{
* Este trabalho foi extraido da Tese de Mestrado em Medicina Veterinária apresentada pelo primeiro autor ao Curso de Pós-graduação em Patologia Veterinária - subárea - Ornitopatologia da Faculdade de Veterinária da Universidade Federal Fluminense.

** Prof. Adjunto da Disciplina de Doenças Parasitárias da Faculdade de Veterinária da Universidade Federal Fluminense, Rua Vital Brazil Filho, 64 - Niterói, RJ - CEP 24240-340.

*** Prof. Adjunto da Disciplina de Anatomia Patológica da Faculdade de Veterinária da Universidade Federal Fluminense.
} 
Duarte (1981), com base em revisão bibliográfica e também em achados de necropsia, elaborou uma lista de helmintos de animais domésticos do estado do Rio de Janeiro, onde não foi incluída a galinha-d'angola.

Baseado na falta de informações sobre as helmintoses dessa ave no Brasil, o presente trabalho tem por objetivos estudar os aspectos patológicos, a prevalência e a intensidade de infecção causadas por nematóides e cestóides de galinhas-d'angola, criadas extensivamente no estado do Rio de Janeiro.

\section{Material e métodos}

Após o exame clínico de cada ave, que consistiu na inspeção de pele, penas, olhos, mucosas e excrementos e também na palpação da musculatura peitoral e do osso esterno, procedeu-se à necropsia de 36 galinhas-d'angola oriundas de criações extensivas do estado do Rio de Janeiro empregandose a técnica de necropsia segundo Zander e Mallinson (1991).

Os helmintos encontrados, nos diferentes órgãos examinados, foram coletados e fixados em AFA (93\% álcool, $70 \% \mathrm{GL}$, $5 \%$ formol comercial e $2 \%$ ácido acético), contados e preparados de acordo com as técnicas helmintológicas. Os nematóides foram identificados segundo Yamaguti (1961) Costa e Freitas (1962), Levine (1980), Ruff (1991) e Vicente et al. (1995) e os cestóides segundo Wardle e McLeod (1952), Reid (1962) e Freitas e Costa (1962).

As formas larvares do nematóide Ascaridia numidae encontradas foram diferenciadas dos helmintos adultos pela ausência de órgãos sexuais desenvolvidos. Elas foram obtidas através de raspagem da mucosa do intestino delgado com lâmina de vidro de microscopia.

As alterações macroscópicas observadas nos órgãos parasitados foram descritas, assim como fragmentos desses órgãos foram coletados, fixados em formol a $10 \%$ e enviados ao Laboratório de Anatomia Patológica, onde foram processados, corados pela hematoxilina-eosina e montados, de acordo com as técnicas histológicas usuais segundo Behmer et al. (1976).

\section{Resultados}

Os sinais clínicos mais freqüentes observados nas aves parasitadas foram: penas arrepiadas, sem brilho e mau estado de carne caracterizado por atrofia muscular, principalmente visualizada na musculatura peitoral e sinuosidade do osso esterno. A diarréia foi observada somente em dois animais.

No Quadro 1 estão listados os helmintos identificados e suas respectivas prevalências, intensidades de infecção e amplitudes de variação. Heterakis gallinarum e Ascaridia numidae apresentaram maior prevalência, assim como maior intensidade de infecção entre as aves necropsiadas.

Formas larvares de $A$. numidae foram encontradas em $50 \%$ das galinhas-d'angola necropsiadas. Essas larvas estavam localizadas principalmente no jejuno e íleo, nos cecos, moela e cólon-reto, em pequenas quantidades em algumas aves. Um número de larvas entre um e 100 foi encontrado em dez aves $(27,8 \%)$, um número entre 101 e 200 larvas em três aves $(8,3 \%)$, entre 201 e 300 em duas $(5,5 \%)$ e mais que $300 \mathrm{em}$ três $(8,3 \%)$. Em três das 27 aves parasitadas por $A$. numidae existiam apenas formas larvares.

O Quadro 2 mostra as alterações macroscópicas e microscópicas observadas nos órgãos parasitados de galinhasd'angola no estado do Rio de Janeiro associadas a cada helminto.

\section{Discussão}

Das seis espécies de nematóides encontradas, Dispharynx nasuta não havia sido registrado em galinhas-d'angola no Brasil. Os registros são para galinhas domésticas, pombos e perus de acordo com Vicente et al. (1995). As outras espécies de nematóides e de cestóide identificadas encontramse relacionadas na lista de Costa et al. (1986) e no catálogo de Vicente et al. (1995).

A prevalência dos helmintos em galinhas-d'angola encontrada na presente pesquisa difere dos resultados encontrados em outros países. Vercruysse et al. (1985) em Burkina Faso, Fabiyi (1972) na Nigéria e Boado et al. (1991) em Cuba, registraram maior prevalência de Subulura suctoria. Em Gana, Hodasi (1976) registrou Subulura brumpti, como o mais prevalente. Na União Soviética, Haziev e Khan (1991) constataram que o nematóide Heterakis gallinarum foi o helminto mais prevalente, dado esse semelhante ao da presente pesquisa.

A maioria das galinhas-d'angola necropsiadas albergava entre uma e 100 larvas de $A$. numidae no intestino delgado. Apesar de diversos autores tais como Souza et al. (1997) no Brasil, Macchioni (1968) na Itália e Matta e Ahluwalia (1979) na Índia terem registrado a presença comum de larvas de $A$. numidae nas infecções naturais, dados sobre a prevalência e número de larvas não foram registrados. Esses dados são considerados importantes, pois as formas larvares são patogênicas para galinhas-d'angola, segundo os investigadores citados.

As graves alterações macroscópicas encontradas no proventrículo das galinhas-d'angola causadas por $D$. nasuta foram semelhantes às reportadas por Vassilev e Jooste (1991) em aves no Zimbábue, com exceção das lesões nodulares proventriculares, mais numerosas nas proximidades da junção com o esôfago, encontradas por estes autores. Diferentemente destes pesquisadores, com relação às alterações microscópicas proventriculares, não foram observadas no presente trabalho edema interglandular, hiperqueratose e paraqueratose do epitélio glandular e nem trombose de vasos sangüíneos. De acordo com Orlandi (1979), foi observado nos casos mais graves de infecção por $D$. nasuta em galinhas-d'angola na Itália, uma substituição do parênquima normal por tecido conjuntivo, alteração essa também encontrada na presente pesquisa.

Pelas alterações macro e microscópicas observadas, o $D$. nasuta se mostrou um heiminto bastante patogênico, sendo muito agressivo à mucosa do proventrículo.

A ausência de alterações no proventrículo, moela e cecos estavam relacionadas à pequena quantidade de Capillaria spp. encontrada nesses órgãos. As lesões macroscópicas e microscópicas ocasionadas por Capillaria spp., no intestino delgado, foram de pouca extensão e gravidade. Entretanto, segundo Levine (1980), espécies intestinais de Capillaria 
Quadro 1: Prevalência, intensidade média de infecção e amplitude de variação dos nematóides e do cestóide de galinhasd'angola no estado do Rio de Janeiro.

\begin{tabular}{|c|c|c|c|c|c|}
\hline \multirow[t]{2}{*}{ Helmintos } & \multirow[t]{2}{*}{ Habitat } & \multirow[t]{2}{*}{ Prevalência } & \multicolumn{2}{|c|}{ Intensidade média de infecção } & \multirow{2}{*}{$\begin{array}{c}\text { Amplitude de } \\
\text { variação }\end{array}$} \\
\hline & & & $\begin{array}{c}\text { Entre os } \\
\text { necropsiados }\end{array}$ & $\begin{array}{l}\text { Entre os } \\
\text { parasitados }\end{array}$ & \\
\hline $\begin{array}{l}\text { Heterakis gallinarum } \\
\text { (Schrank, 1788) Freeborn, } 1904 .\end{array}$ & Cecos. & $100,0 \%$ & 194,08 & 194 & $13-785$ \\
\hline $\begin{array}{l}\text { Ascaridia numidae } \\
\text { (Leiper, 1908) Travassos, } 1913 .\end{array}$ & $\begin{array}{l}\text { Jejuno } \\
\text { îleo. }\end{array}$ & $75,0 \%$ & 48,80 & 63 & $1-610$ \\
\hline Capillaria spp. Zeder, 1800. & $\begin{array}{l}\text { moela, proventrículo, cecos } \\
\text { e intestino delgado. }\end{array}$ & $52,8 \%$ & 30,08 & 57 & $2-755$ \\
\hline $\begin{array}{c}\text { Raillietina (Paroniella) magninumida } \\
\text { Jones, } 1930 .\end{array}$ & $\begin{array}{c}\text { Duodeno } \\
\text { Jejuno. }\end{array}$ & $47,2 \%$ & 20,33 & 43 & $1-208$ \\
\hline $\begin{array}{c}\text { Dispharynx nasuta } \\
\text { (Rudolphi, 1819) Stiles e Hassell, } 1920 .\end{array}$ & Proventrículo. & $44,4 \%$ & 39,50 & 89 & $6-251$ \\
\hline $\begin{array}{c}\text { Eucoleus perforans } \\
\text { (Kotlán e Orosz, 1931) Lopez-Neyra, 1946. }\end{array}$ & $\begin{array}{c}\text { Papo } \\
\text { Esôfago. }\end{array}$ & $5,5 \%$ & 0,55 & 10 & $9-11$ \\
\hline $\begin{array}{c}\text { Oxyspirura mansoni } \\
\text { (Cobbold, 1879) Ransom, } 1904 .\end{array}$ & $\begin{array}{c}\text { sob a membrana nictitante } \\
\text { do olho. }\end{array}$ & $2,8 \%$ & 0,08 & 3 & 3 \\
\hline
\end{tabular}

Quadro 2: Alterações macroscópicas e microscópicas encontradas nos órgãos parasitados de galinhas-d'angola no estado do Rio de Janeiro, associadas a cada helminto encontrado na pesquisa.

\begin{tabular}{|c|c|c|c|c|}
\hline Helmintos & $\begin{array}{c}N^{\circ} \text { de aves com } \\
\text { alteracōes }\end{array}$ & $\begin{array}{l}\text { Óraão } \\
\text { parasitado }\end{array}$ & Alteracões macroscópicas & Alteracões micros cópicas \\
\hline H. gallinarum & 8 & Cecos & $\begin{array}{l}\text { Cecos dilatados com grande } \\
\text { acúmulo de fezes, espessamento, } \\
\text { congestão e hemorragias } \\
\text { petequiais na mucosa }\end{array}$ & Tiflite crônica \\
\hline A. numidae & 13 & $\begin{array}{l}\text { Intestino } \\
\text { delgado }\end{array}$ & $\begin{array}{l}\text { Obstrução do ileo e porção final do } \\
\text { jejuno, espessamento, congestão } \\
\text { e focos de hemorragia na mucosa, } \\
\text { presença de quantidade excessiva } \\
\text { de muco no lúmen e aumento e } \\
\text { congestão dos nódulos linfáticos } \\
\text { intestinais }\end{array}$ & $\begin{array}{l}\text { Enterite crônica. Presença de larvas com } \\
\text { maior freqũência no lúmen das glândulas de } \\
\text { Lieberkühn, entre as vilosidades intestinais, no } \\
\text { revestimento da mucosa próximo às criptas } \\
\text { intestinais e, mais raramente, inseridas } \\
\text { profundamente na mucosa, acompanhadas } \\
\text { por uma intensa reação inflamatória crônico- } \\
\text { ativa, com predominância de heterófilos. }\end{array}$ \\
\hline \multirow[t]{2}{*}{$\begin{array}{l}\text { Capillaria } \\
\text { spp. }\end{array}$} & 0 & $\begin{array}{c}\text { Proventrículo, } \\
\text { moela e } \\
\text { cecos }\end{array}$ & Ausentes & Ausentes \\
\hline & 10 & $\begin{array}{l}\text { Intestino } \\
\text { delgado }\end{array}$ & $\begin{array}{l}\text { Congestão, petéquias e espessa- } \\
\text { mento da mucosa }\end{array}$ & $\begin{array}{l}\text { Enterite crônica. Em uma das aves verificou-se } \\
\text { área de necrose e uma inflamação crônico- } \\
\text { ativa num possivel local de agressão do } \\
\text { parasita }\end{array}$ \\
\hline $\begin{array}{c}R . \\
\text { magninumida }\end{array}$ & 9 & $\begin{array}{l}\text { Intestino } \\
\text { delgado }\end{array}$ & $\begin{array}{l}\text { Congestão e presença de } \\
\text { petéquias }\end{array}$ & Enterite crônica \\
\hline D. nasuta & 16 & Proventrículo & $\begin{array}{l}\text { Dilatação, congestão da serosa, } \\
\text { excesso de muco na luz, presença } \\
\text { de erosões e pontos hemorrágicos } \\
\text { na mucosa que se encontrava } \\
\text { congesta e espessada. }\end{array}$ & $\begin{array}{l}\text { Proventriculite crônica com espessamento da } \\
\text { mucosa, esclerose, presença de áreas de } \\
\text { úlcera com destruição total do epitélio, } \\
\text { distensão das glândulas mucosas } \\
\text { proventriculares e presença de grande } \\
\text { quantidade de muco na luz do órgão. }\end{array}$ \\
\hline E. perforans & 2 & $\begin{array}{l}\text { Papo e } \\
\text { esôfago }\end{array}$ & Petéquias e congestão & $\begin{array}{l}\text { Parasitas localizados profundamente no } \\
\text { epitélio estratificado escamoso do papo, } \\
\text { abundante reação inflamatória do tipo } \\
\text { flegmonoso, distensão das glândulas mucosas } \\
\text { presentes na túnica própria do papo, na região } \\
\text { próxima ao esôfago. }\end{array}$ \\
\hline O. mansoni & 0 & Olhos & Ausentes & Ausentes \\
\hline
\end{tabular}


como $C$. caundinflata e $C$. obsignata podem ocasionar uma enterite severa com espessamento da mucosa intestinal. Hemorragias podem estar presentes e efeitos graves, até mesmo morte, podem ocorrer com poucos helmintos recuperados na necropsia.

Reis e Nóbrega (1938), no Brasil, observaram que a ocorrência de $E$. perforans causava um quadro clínico de tristeza, apatia e alta mortalidade. Na maioria dos casos foi observada uma dilatação do papo. Massas circulares fáceis de destacar e espessamento da mucosa, às vezes coberta de numerosas papilas, formavam pregas avantajadas. Estes sinais clínicos e lesões não foram verificados nas aves parasitadas por esse nematóide no presente trabalho. Estes mesmos investigadores também encontraram o helminto $E$. perforans localizado profundamente no epitélio do papo, porém em infecções concomitantes com o protozoário Trichomonas sp. nesse órgão, ocasionando graves alterações microscópicas, como inflamação cruposa, necrose do epitélio, e proliferação epitelial com corneificação progressiva. Estas lesões foram diferentes das observadas no presente trabalho.

Microscopicamente constatou-se que, apesar da baixa intensidade média de infecção encontrada na presente pesquisa, as alterações provocadas pelo E. perforans foram consideradas graves, principalmente no que diz respeito à intensa reação inflamatória observada.

As alterações causadas por formas adultas e larvares de $A$. numidae foram semelhantes às encontradas por outros pesquisadores tais como Macchioni et al. (1978) e Souza et al. (1997). Todavia, nenhum desses autores registrou o aumento e a congestão dos nódulos linfáticos intestinais, o que foi constatado nesta pesquisa.

\section{Referências bibliográficas}

BEHMER, A. O., TOLOSA, E.N.C., FREITASNETO, A.G. Manual técnico para histologia normal e patológica. São Paulo: EDART, 1976.

BOADO, E., ZALDIVAR, L., LOPEZ, S., GONZALES, A., QUINTERO, D. Diagnóstico y estudio patomorfológico de las enfermedades de la gallina de Guinea. Rev Cubana Cienc Avícola, v. 18, n. 2, p. 156161, 1991.

COSTA, H.M.A., FREITAS, M.G. Alguns parasitos de animais domésticos dos estados do Maranhão e Piauí. Arq. Esc. Vet. UFMG, v. 14, p. 35-46, 1962.

COSTA, H.M.A, LEITE, A.C.R., GUIMARÃES, M.P., LIMA, W.S. Distribuição de helmintos parasitos de animais domésticos no Brasil. Arq. Bras. Med. Vet. Zoot. , v. 38, p. 465-579, 1986.

DUARTE, M.J.F. Helmintos parasitos de animais domésticos no Estado do Rio de Janeiro. Arq. Esc. Vet. UFMG, v. 33, n.1, p. 67-98, 1981.

FABICHAK, I. Criação de galinhas-d'angola. São Paulo: Nobel, 1997.

FABIYI, J.P. Studies on parasites of the grey-breasted helmet guinea fowl (Numida meleagridis galeata pallas) of the Vom area of the Benue Plateau State, Nigeria. I. Helminth parasites. Bull. Epizoot. Dis. Africa, v. 20, n. 3, p. 235-238, 1972.

FREITAS, M.G., COSTA, H.M.A. Raillietina (Paroniella) magninumida Jones, 1930. Arq. Esc. Vet. UFMG, v. 14, p. 171-175, 1962.

HAZIEV, G.Z., KHAN, S.A. Helminthes of guinea fowl (Numida meleagris) in Bashkir ASSR. Vet. Parasitol., v. 38, n. 4, p. 349-353, 1991.
Microscopicamente verificou-se que as severas alterações estavam relacionadas principalmente às formas larvares de A. numidae, como também constataram Macchioni et al. (1978). As localizações dessas larvas foram semelhantes aos achados de Macchioni (1968), Macchioni et al. (1978), Mabon e Reid (1973) e Souza et al. (1997). Entretanto, a presença de larvas no revestimento da mucosa intestinal não foi registrada por estes investigadores.

Apesar da elevada intensidade média de infecção, $H$. gallinarum mostrou-se pouco patogênico. Somente em cargas parasitárias muito elevadas foram observadas alterações macroscópicas. Essas alterações foram semelhantes às encontradas por León e Soldevila (1978) em uma criação extensiva de galinhas-d'angola em Porto Rico. Esses autores encontraram como lesões cecais, causadas pelo $H$. gallinarum, espessamento da mucosa e várias hemorragias petequiais. Esses achados vêm corroborar investigađiores como Lund e Chute (1974) e Levine (1980), que consideram o $H$. gallinarum um helminto normalmente pouco patogênico.

Em função da baixa intensidade de infecção, 0 . mansoni não determinou lesões oculares observáveis. Todavia, segundo Ruff (1991), as aves onde esse nematóide está presente podem demonstrar uma oftalmia peculiar, com lacrimejamento, inflamação severa nos olhos, inchação da membrana nictitante e presença de coleção caseosa embaixo das pálpebras.

O cestóide $R$. magninumida, na intensidade média de infecção registrada, ocasionou alterações macroscópicas e microscópicas consideradas de pouca gravidade. Até então, a patogenicidade desse helminto era considerada desconhecida, segundo Reid (1991).

HODASI, J.K.M. The helminth parasites of the helmet guinea fowl (Numida meleagris galeata pallas) in Ghana. Bull. An. Health Prod. Africa, v. 24, n. 1, p. 81-87, 1976.

KISS, J., RAMOS, M.A.P. Beleza Selvagem. Rev Globo Rural, n. 134, p. 40-46, 1996.

LEÓN, D., SOLDEVILA, M. Capillaria annulata and Heterakis gallinanum infections in guinea fowl in Puerto Rico - a case report. J. Agric. Univ. Puerto Rico, v. 62, n. 4, p. 428-430, 1978.

LEVINE, N.D. Nematode parasites of domestic animals and man. Minneapolis: Burguess Publ. Co, 1980.

LUND, E.E. , CHUTE, A.M. The reproductive potencial of Heterakis gallinarum in various species of galliform birds: implications for survival of $H$. gallinarum and Histomonas meleagridis to recent times. International J. Parasitol., v. 4, n. 5, p. 455-461, 1974.

MABON, J.L., REID, W.M. Tissue stages in the development of Ascaridia numidae from the guinea fowl (Numida meleagris). J. Parasitol., v. 59, n. 6, p. 1012-1015, 1973.

MACCHIONI, G. Ascaridia numidae (Leiper, 1908) Travassos, 1913 in guinea fowl (Numida meleagrisL.) in Italy. An. Fac. Med. Vet. Pisa, v. 21, p. 135-143, 1968.

MACCHIONI, G., MARCONCINI, A., FUSO, F. Pathogenic effects of $A$. numidae in the guinea fowl. An. Fac. Med. Vet. Pisa, v. 31, p. 115126, 1978.

MATTA, S.C., AHLUWALIA, S.S. A note on the pathogenesis of Ascaridia numidae larvae in the gut of guinea-fowls. Indian J. An. Sci., v. 49, n. 1, p. $72-74,1979$. 
ORLANDI, M. Acuarosis (Dispharagosis) of birds. First report in Italy of Acuarosis (Dispharogosis) by Dispharynx nasuta (Rudolphi, 1819) in the guinea-fowl (Numida meleagrisL.). An. Fac. Med. Vet. Pisa, v. 32, p. 105-110, 1979.

REID, W.M. Chicken and Turkey Tapeworms: handbook to aid in the identification and control of tapeworms found in the United States of America. EUA: University of Georgia Poultry Department, 1962.

REID, W.M. Cestodes and Trematodes. In: CALNEK, B.W. , BARNES, H.J., REID, W.M. et al. Diseases of Poultry. 9. ed. EUA: lowa State University Press, 1991.p. 764-768.

REIS, J., NÓBREGA, P. Sôbre as lesões produzidas pela Capillaria perforans Kótlan \& Orosz nas aves domésticas. Arq. Inst. Biol. São Paulo, v. 9, p. 21-24, 1938.

RUFF, M.D. Nematodes and Acanthocephalans. In: CALNEK, B.W., BARNES, H.J., REID, W.M. et al. Diseases of Poultry. 9. ed. EUA: lowa State University Press, 1991. p. 731-763.

SOUZA, P.C.A., RODRIGUES, M.L.A., LOPES, C.W.G. Um surto de ascaridiose em uma criação intensiva de galinhas-d'angola. Revta. Bras. Med. Vet., v. 19, n. 5, p. 206-208, 1997.
VASSILEV, G.D., JOOSTE, R. Pathology and Taxonomy of Synhimantus (Dispharynx) nasuta infesting bantanms and guineafowls in Zimbabwe. Bull. An. Health Prod.Africa, v. 39, n. 1, p. 2730, 1991.

VERCRUYSSE, J., HARRIS, E. A., BRAY, R.A. et al. Survey of Gastrintesinal Helminthes of the Common Helmet Guinea Fowl (Numida meleagris galeata) in Burkina Faso. Avian Dis., v. 29, n. 3 , p. 742-745, 1985.

VICENTE, J.J., RODRIGUES, H.O., GOMES, D.C., PINTO, R.M.Nematóides do Brasil. Parte IV: Nematóides de aves. Rev. Bras. Zool., v. 12, n. 1, p. 1-273, 1995.

ZANDER, D.V., MALLINSON, E.T. Principles of Disease Prevention: diagnosis and control. In: CALNEK, B.W., BARNES, H. J., REID, W.M. et al. Diseases of Poultry. 9. ed. EUA: lowa State University Press, 1991.p. 3-44.

WARDLE, R.A., McLEOD, J.A. The Zoology of Tapeworms. Minneapolis: Univ. of Minnesota Press, 1952.

YAMAGUTI, S. The Nematodes of Vertebrates: Systema Helminthum. 3 v., part. I III. New York: Interscience, 1961. 